\title{
De la crónica al ser profundo: pintura y cultura popular mexicana en Luis Cardoza y Aragón ${ }^{1}$
}

\section{Leonel Delgado Aburto}

Recepción: 1 de setiembre de 2015 / Aprobación: 5 de octubre de 2015

\section{Resumen}

Este artículo analiza algunas líneas esenciales de la intervención de Luis Cardoza y Aragón en el debate sobre la cultura mexicana posrevolucionaria, particularmente en la pintura y la cultura popular. El ensayo argumenta que Cardoza parte del acercamiento característico de la crónica literaria pero que su texto se mezcla con el ensayo y la crítica de arte. Los textos de Cardoza están orientados por la visión radical de las vanguardias, pero no se fijan en la vida urbana, sino en el análisis del ser mexicano. En su discurso se muestra la preocupación por la construcción nacional así como el uso de una perspectiva enriquecida por el cosmopolitismo estético de las vanguardias.

\section{Palabras clave}

Cardoza y Aragón, crónica literaria, México, vanguardias, cultura mexicana

\section{Abstract}

This article discusses some essential lines of the intervention of Luis Cardoza y Aragón in the debate on the post-revolutionary Mexican culture, particularly the Mexican art and popular culture. Although Cardoza began his approach using the model of literary chronicle, his texts combine essay and art criticism. Cardoza's texts are guided by a radical vanguardist vision, however they do not refer to urban life but to the analysis of being Mexican. In his approach, there is a concern for national construction and the use of a perspective enriched by the cosmopolitanism of the avant-garde aesthetic.

\section{Keywords}

Cardoza y Aragón, literary chronicle, Mexico, avant-garde, Mexican culture

1 Este articulo es resultado parcial del proyecto de investigación "Exilio, diáspora y peregrinaje cultural: escritores centroamericanos de las (post)vanguardias en México y los Estados Unidos”, proyecto financiado por el Fondo para el Desarrollo Científico y Tecnológico (FONDECYT), número 1150254. Agradezco a Claudia Páez y Millaray Salinas, tesista y ayudante respectivamente, por su apoyo en la investigación.

2 Nicaragüense. Ph. D., Hispanic Languages and Literatures, University of Pittsburgh. Profesor Asistente, Centro de Estudios Culturales Latinoamericanos, Universidad de Chile. Correo electrónico: Idelga_ni@yahoo.com 


\section{Resumo}

Este artigo aborda algumas linhas essenciais da intervenção de Luis Cardoza y Aragón no debate sobre a cultura mexicana pós- revolucionária , particularmente a pintura e a cultura popular. O ensaio argumenta que Cardoza inicia seu abordagem com a crônica literária, mas seu texto é misturado com o ensaio e crítica de arte. Os textos de Cardoza são guiados pela visão de vanguarda radical , mas não olhar para a vida urbana, mas na análise de ser mexicano. Em seu discurso a preocupação com a construção nacional e a utilização de uma perspectiva enriquecida pelo cosmopolitismo da estética na avant-garde.

\section{Palavras chave}

Cardoza y Aragón , crônica literária, México , vanguarda, Cultura Mexicana

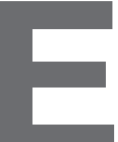

n el prólogo a las Poesías completas de Luis Cardoza y Aragón (1977), José Emilio Pacheco afirma que el libro de crónicas de Cardoza sobre su visita a Marruecos, Fez, ciudad santa de los árabes, es una "muestra casi final de un género... que derrotaron el cine, el turismo y el transporte aéreo" (Pacheco, 1977, p. 11)3. Pacheco alude, por supuesto, a la crónica literaria y más precisamente a la crónica modernista. De hecho, refiere que Cardoza había sido "estimulado por Enrique Gómez Carrillo", es decir, el cronista modernista por excelencia, a ir a Marruecos. En esa coyuntura que junta a dos guatemaltecos en Europa se puede percibir varios estados liminales, fronteras y límites, que resultan bastante sugerentes. A saber: la frontera entre el modernismo decadente y la vanguardia ascendente, y paralelamente la explotación de las fronteras orientalistas figuradas en Marruecos que habían sido tema importante de algunos cronistas centroamericanos, entre ellos el mismo Gómez Carrillo o Arturo Ambrogi (Roque-Baldovinos, 2009). Asimismo, aparece demarcado el final, según Pacheco, de un género algo pródigo, la crónica literaria. Este género, sin embargo, ejercerá todavía una impronta significativa en la vanguardia, viviendo periódicos auges, como, en parte, parece probar la obra misma de Cardoza. De hecho, es la crónica modernista (y quizá se debería decir, más bien, la crónica moderna) un género intersticial, aseveración que es de por sí un tópico en los estudios sobre la materia, verbigracia la siguiente aseveración de Graciela Montaldo:

La literatura de la época [y con esto Montaldo se refiere al modernismo] ya era claramente la transacción entre diferentes escrituras y el pasaje entre esas diferencias constituye lo nuevo: una colocación entre la autonomía y la profesionalización, entre la estetización y la divulgación. Quien sobrevivía a las diferencias, colonizándolas y territorializándolas, era moderno (Montaldo, 2013, p. 13).

3 Sobre Fez, ciudad santa, véase Rodríguez Cascante, 2012. 
Por supuesto, todo esto apunta a decir que se equivocaba parcialmente Pacheco al dar por muerta a la crónica. Declinan, sin duda, dentro del género algunos afanes y énfasis del modernismo. Sin embargo varios de los vanguardistas hispanoamericanos serán también grandes cronistas. Durante la coyuntura de los años 1920s y 1930s la crónica, al decir de Viviane Mahieux, se entrelazará con la vida urbana, y escribir la ciudad será participar de su pasado y presente, revivificando tradiciones e historias orales (Mahieux, 2012, p. 13). Entre algunos autores fundamentales que Mahieux estudia están Salvador Novo, Cube Bonifant, Roberto Arlt, Alfonsina Storni, Mario de Andrade, todos relacionados con ámbitos urbanos específicos: México, D.F., Buenos Aires y Sao Pablo. Como dice la autora:

[The chronicle] absorbed and reflected some of the most urgent issues put forth by the avant-gardes of the period-namely, a questioning of cultural hierarchies, a political engagement, a will to provoke a complacent public, and at the same time, a belief in the role of art and literature in the construction of a modern identity [La crónica absorbió y reflejó algunos de los más urgentes asuntos puestos en evidencia por las vanguardias del período-a saber: el cuestionamiento de las jerarquías culturales, el compromiso político, la voluntad de provocar a un público complaciente, y al mismo tiempo, la creencia en el rol del arte y la literatura en la construcción de la identidad moderna] (Mahieux, 2012, p. 4).

Ante esta identificación urbana de la crónica y su característica ambigüedad genérica, quisiera hacer ver el cambio retórico e ideológico que Cardoza le impone a los relatos cercanos a la crónica, convirtiéndolos en indicadores de la identidad, mexicana o guatemalteca. Así los textos devienen objetos inmanentes, orientados menos a representar un espíritu urbano que un ser nacional profundo e híbrido. Quizá lo más sobresaliente de tal operación sea que no implica un giro conservador, sino que, al contrario, comparte la radicalidad de la vanguardia, incluyendo algunas características que Mahieux señala para la crónica literaria durante las vanguardias.

Para ilustrar algunos aspectos del proyecto de Cardoza, tomaré en este artículo dos momentos sucesivos de tal inscripción identitaria y retóricamente fronteriza (entre el ensayo y la crónica, entre la historia del arte y la poesía). En primer lugar, su lectura de la pintura mexicana, La nube y el reloj (1940), que detalla toda una coyuntura histórica de la relación entre arte y sociedad del México posrevolucionario. Esta incursión de Cardoza en la crítica de arte tendrá continuación en la interpretación de la cultura nacional y popular, por medio de los textos recogidos en Apolo y Coatlicue (1944) que incluye ensayos, crónicas, recesiones, crítica de arte, retratos y otros textos mixtos escritos y publicados entre las décadas de 1930 y 1940, y que Cardoza concibe como "tomo II de La nube y el reloj", (ver el "Prefacio" a Apolo y Coatlicue). Si bien estos escritos heterogéneos no pueden ser enmarcados dentro del orden urbano de la crónica, sí se prestan para ilustrar un momento crítico en que los textos se ven tironeados por intenciones o agendas intelectuales contradictorias, que en el caso de Cardoza parecen ser no solamente las de un escritor vanguardista, 
sino de uno que pugna por insertarse en el ámbito cultural mexicano, pero sin dejar de indicar una pertenencia excéntrica o exiliada. De hecho se podría argumentar que la intención de Cardoza es hasta cierto punto escapar de la crónica en su sentido más liviano y transaccional, por no decir comercial (modelo en que habría que volver a mencionar a Gómez Carrillo). Lo que Cardoza parece encontrar en México es un debate complejo sobre la identidad nacional ${ }^{4}$, en el que intervendrá con una perspectiva universalista, explorando el espacio reterritorializado por los movimientos de vanguardia.

\section{Exilio e inmanencia}

Como puede suponerse, Luis Cardoza y Aragón es un sujeto literario más que sugerente para investigar las cuestiones del exilio, la diáspora y el peregrinaje cultural de escritores vanguardistas centroamericanos que han vivido en México y los Estados Unidos. Las tres variables en discusión (exilio, diáspora, peregrinaje) conforman un conjunto en que se expresa la excentricidad del escritor hispanoamericano y, en particular, centroamericano. Si bien no todos los escritores centroamericanos son necesariamente excéntricos en el sentido que lo planteo aquí, es razonable pensar que la salida del espacio geográfico centroamericano hacia otras múltiples regiones, es una constante desde al menos el modernismo. Cardoza inició su carrera literaria, como se puede dejar ver por su relación con Gómez Carrillo y por sus crónicas tempranas, con el ímpetu del peregrino marcado todavía por el espíritu cosmopolita modernista. Con su viaje a Europa, se mete de cabeza en las transformaciones estéticas y políticas de las vanguardias, experimentando posteriormente de forma apasionada los procesos de construcción del campo cultural mexicano y sus debates principales, para luego participar en un intento de construcción cultural de lo nacional en Guatemala, hasta el golpe de estado de 1954 que corta tal proceso emancipador. Cardoza vive, consiguientemente, durante largos años como exiliado en México, hasta su muerte.

Durante esta larga trama, Cardoza va a atravesar diversas variables y roles de la excentricidad y la desterritorialización. ¿Qué nos enseña la experiencia de Cardoza en relación con una conceptualización general del peregrinaje y el exilio? Creo que para Cardoza la condición de exilio o de excentricidad es la de una acción intelectual radical y que el modelado de tal acción está constituido, obviamente, por el espíritu de las vanguardias. Es importante señalar que en el caso de Cardoza, como en el de otros casos centroamericanos ${ }^{5}$, no basta

$4 \quad$ Como se sabe, la cuestión de la identidad mexicana implica un debate muy amplio. Como muestra se puede recordar la conocida antología de José Luis Martínez, El ensayo mexicano moderno (1958). Martínez describe en su introducción, algunos momentos fundamentales para el pensamiento de la identidad nacional en el siglo XX: los Ateneístas, los Contemporáneos, que enfatizan la inmanencia de la obra de arte, y una generación influenciada por el existencialismo (Martínez, 1958, tomo 1, pp. 22-23). Los textos de Cardoza que discuto después aparecen relacionados con estas tres coordenadas.

Entre autores canónicos de Centroamérica, por ejemplo: Darío, Gómez Carrillo, Eunice Odio. 
para explicar su postura el modelo típico en que el exiliado espera volver a su tierra y a un sistema determinado de vida, en un proceso de alteración y luego reposición de un más o menos soñado esplendor patrio ${ }^{6}$. El punto de llegada o de retorno, en el caso de Cardoza es incierto o no está creado. En estas circunstancias la reterritorialización, entendida como refundación cultural del sujeto en el espacio (trans)nacional, se vuelve fundamental. Aún más, diríase que el estilo de su exilio o su peregrinaje es la reterritorialización ${ }^{7}$. En referencia al pintor Carlos Mérida, Cardoza escribió en La nube y el reloj: "Es el caso estrafalario del americano que regresa americano a América después de una larga permanencia en Europa" (Cardoza y Aragón, 1940, p. 47). Es claro que esa paradoja alude al propio Cardoza y, de forma general, al escritor centroamericano excéntrico.

Para tratar de explicar esta hipótesis me referiré a la tensión que se establece entre inmanencia y universalismo en la obra de Cardoza. En primer lugar, el concepto de inmanencia, retomado de Gilles Deleuze, tiene una doble aplicación, como espacio discursivo o campo cultural, y como índice de autonomía del mismo discurso. En segundo lugar, el universalismo, del que Cardoza participa, querrá leer la cultura nacional en varios niveles (estético, cultural y político), e implica tanto una normativa como un vínculo comunitario, es decir, una estética y un discurso identitario nacional.

Para explicar la inmanencia, en ¿Qué es la filosofía?, Deleuze y Guattari integran variables que pertenecen al campo o la materialidad cultural. La base de tal materialidad es la desterritorialización de artesanos, mercaderes y filósofos en las ciudades de la Grecia antigua. Grecia ofrece un "medio de inmanencia" en que se hacen posibles el placer de la asociación, la amistad y la rivalidad (Deleuze y Guattari, 2011, pp. 88-89). Fundamentalmente, elementos que conforman un campo cultural moderno, en que los méritos son atributos no agotados por las categorías de clase (o en el caso de un exiliado o desterritorializado, de nacionalidad) sino desplegados en espacios de afectos y controversias. Es evidente que con la modernización latinoamericana, sobre todo desde finales del siglo XIX esta "sociabilidad pura" entre los grupos ilustrados va articulando los campos culturales de la región. Así, por medio de la excentricidad de las redes sensibles e intelectuales -localizadas en Europa o en países que congregan por razones históricas fuerzas culturales importantes, como lo es el México posrevolucionario- se constituye un campo propicio para el debate y el reordenamiento de conceptos, para el despliegue de la serie infinita de la amistad y la rivalidad. La desterritorialización de Cardoza y

6 Para la discusión sobre las diferentes tipologías de movilidad transnacional (emigrados, refugiados, exiliados, cosmopolitas), ver Sznajder y Roniger, 2013, particularmente pp. 31-63.

7 Desterritorialización y reterritorialización son inseparables, dicen Deleuze y Guattari (2011, p. 86) y los conceptos mismos de Estado y Ciudad los implican como procesos: apropiación fundacional de territorios, en el caso del Estado, con el consiguiente desplazamiento de pueblos originarios; y el desarrollo inmanente de vida comercial y política en las ciudades (Deleuze y Guattari, 2011, p. 87). 
Aragón implica, según creo, no tanto la pérdida de un vínculo con la patria (o no solo eso), sino el ingreso a un espacio de inmanencia transnacional que eventualmente hace posible la participación del espacio polémico de la cultura posrevolucionaria mexicana y la operación de construcción intelectual de lo nacional guatemalteco.

A su vez, la forma en que Cardoza defenderá durante el período mexicano inicial la autonomía de la obra de arte, tomando posición en contra de un arte ideológico así como condenando el pintoresquismo y el folklore, es decir, su opción radical por un arte vanguardista, aunque marcado por la identidad, está orientada por esa base o espacio intercomunicado y en una lógica de inmanencia. La inmanencia implica el desarrollo de un campo de debate general que vincula a América y Europa (la transnacionalidad de la vanguardia), y que, de hecho, descentra los debates metropolitanos. Abarca también perspectivas universalistas que Cardoza va a integrar como asunto fundamental.

\section{El universalismo}

Como se sabe, Cardoza realiza una intervención primordial en el debate sobre el arte moderno mexicano. En La nube y el reloj recoge textos muchas veces polémicos sobre pintores imprescindibles dentro del desarrollo del arte contemporáneo, destacando entre ellos a José Clemente Orozco a quien Cardoza considera el pintor más importante de América (Cardoza y Aragón, 1940, p. 122). Cardoza publica, en 1944, lo que él considera una segunda parte de La nube y el reloj, los ensayos recogidos con el título de Apolo y Coatlicue que amplifican la mirada sobre México hacia, por una parte, el ser nacional y por otra, a la cultura nacional-popular así como a algunos letrados notables, llamados por Cardoza al estilo de Rubén Darío, "torres de dios".

En 1953 aparece la edición corregida y sobre todo aumentada de La nube y el reloj, pero ahora el título es más genérico: Pintura mexicana contemporánea (México: Imprenta Universitaria, 1953). El título original se conserva como subtítulo del estudio introductorio: "Comentarios generales: la nube y el reloj". Hay que decir que en este tramo de intensa actividad intelectual, Cardoza ha establecido su voz dentro del debate mexicano, asimilando con intensidad creativa las polémicas del arte revolucionario y de la vanguardia (entre ellos el surrealismo) proyectándolos en lo que podría considerarse un universalismo nacional ${ }^{8}$.

Quisiera destacar algunas líneas sensibles e intelectuales de las posturas de Cardoza en La nube y el reloj. Desde los "Comentarios Generales", Cardoza opta por el universalismo y convoca el "abandono de lo nacional pintoresco" (Cardoza y Aragón, 1940. p. 3), planteando, por tanto, la problemática de lo universal como revolucionario, puesto que la esencia del problema en el contexto mexicano es la del artista y la revolución que, desde otras ópticas debía implicar

8 Véase al respecto, González Mello, 2003. 
un arte proletario o realista ${ }^{9}$. Cardoza condena, por tanto, de manera directa lo que considera un arte académico al servicio del Estado (Cardoza y Aragón, 1940, p. 5). Y si bien en su ensayo sobre Carlos Mérida, plantea un leitmotiv de la obra: la revolución como revelación de lo nacional, incluyendo las fuerzas estéticas (Cardoza y Aragón, 1940, p. 47), Cardoza deja claro que esta revelación no debe implicar una dicción costumbrista, sino por el contrario una conexión con la identidad profunda a partir de una lógica interna de la obra. De hecho, la obra de arte funciona, en los términos de Cardoza, como un indicio problemático de la identidad cultural. Un indicio problemático e incluso inconsciente. Así, Cardoza hace notar con respecto a Mérida: "Todo el problema de la cultura en América se debatía en su pintura” (Cardoza y Aragón, 1940, p. 48). Pero ¿cuál es ese "problema de la cultura"?10 Entre otras cosas, incluye al folklore y el costumbrismo como modelos negativos, representaciones falseadas de una profundidad cultural universalizable. En segundo lugar, se trata de enfrentar una realidad (la "nuestra"), no simplemente ejercer una experimentación vanguardista gratuita trasladando gestos y técnicas europeas. Para Cardoza el arte debe ser, además, radicalmente conceptual, plantearse problemas, o, como él lo dice, dar "interés general a la plástica americana reducida a alusiones pintorescas, [y] a industrializadas artes populares" (Cardoza y Aragón, 1940, p. 48). En este sentido, el arte universal "tiene que ser antes mexicano", asunto que Mérida va a resolver parcialmente con "su obra suprematista". Cardoza enfatiza, en este sentido la inmanencia de la obra, diciendo, por ejemplo: "Un cuadro es una ventana que da a un mundo propio, organizado según un orden poético. Ventana abierta al infinito" (Cardoza y Aragón, 1940, p. 49).

Se podría concluir que la localización conceptual de arte que Cardoza busca, permite estratégicamente varios movimientos de jerarquización y mezcla. Permite convertir la obra de arte y al artista en índices inconscientes de la identidad que trabajan (en) el espacio y (con) los materiales de la mezcla (por eso, se podría pensar que Cardoza avizora en la pintura mexicana, un escenario de transculturación) ${ }^{11}$. De hecho en la jerarquía de Cardoza es la poesía el orden modelador del espacio estético y el poeta moderno, en este caso Baudelaire como modelo, su estratega fundamental. En efecto, en el libro de Cardoza, Baudelaire constituye una especie de paradigma de actitud: la del poeta que

$9 \quad$ Al respecto, véase, entre otra bibliografía, Díaz Arciniega, quien expone en detalle los objetivos institucionales de los proyectos culturales de la Revolución mexicana, por ejemplo, los grandes cometidos del vasconcelismo (Diaz Arciniega, 2010, pp. 45-51). Con respecto a la asimilación que hace Cardoza del modelo disidente e instaurador de antologías de poesía (La nube y el reloj lo es, aunque de pintores), que persiguen la "calidad" formal antes que la enunciación ideológica, véase el "Estudio preliminar" de González Mello a la reedición de La nube y el reloj (2003).

10 Tal problema, dice Cardoza, es decir, la resolución poética de las contradicciones entre universalidad y comunidad, fue resuelto por López Velarde en poesía. López Velarde "fue nuestro Baudelaire" (Cardoza y Aragón, 1940, p. 48).

11 Sin duda el vínculo transnacional de las vanguardias hispanoamericanas, incide en la rearticulación de perspectivas sobre lo propio. Versiones como la transculturación o, posteriormente, lo real maravilloso, ilustran tal proceso. 
escribe sobre arte y de esa manera conecta espacios estéticos y viola linderos retóricos. La inmanencia en Cardoza constituye así un proceso de desborde antes que un señalamiento de funciones estrictas y fronteras acotadas. Se constituye en una forma estratégica de enunciación cultural que partiendo de una separación estética reterritorializa otros espacios y relaciones. En ese sentido al funcionamiento transaccional "entre diferentes escrituras" señalado por Montaldo para el momento modernista, Cardoza agrega, como lo hacen otros vanguardistas, aspectos proyectivos: la construcción subjetiva y estética del sujeto nacional.

\section{Ensayo sobre el ser}

Apolo y Coatlicue no es en su intención más visible la inscripción cronística de la realidad mexicana, sino más bien un plan de búsqueda del ser nacional, proyecto que como se sabe agota una larga serie ensayística y literaria del canon mexicano, motivado por la reconstrucción revolucionaria de lo nacional12. En ese escenario, el arte y la literatura son pensados por Cardoza como expresiones analógicas de la identidad (como ya vimos, Cardoza va a ahondar con particular profundidad en el arte mexicano). Como ha sido señalado por Enrico Mario Santí, hay una evidente presencia de la filosofía de Martin Heiddeger en ese momento histórico de México. Cabría decir que hay la presencia de otras personalidades y movimientos-Breton y el surrealismo, por ejemplo, incluso, en el libro de Cardoza, que contiene precisamente una "Carta a Andre Bretón" (Cardoza y Aragón, 1944, pp. 63-67) ${ }^{13}$. Pero destaco a Heidegger porque me parece que la esencialidad identitaria que Cardoza busca, a la altura de 1943, podría estar motivada por la presencia de aquella filosofía. Según Santí, y con referencia a El arco y la lira, ensayo de Octavio Paz, las ideas de Heidegger llegan a México sobre todo a través de exiliados españoles como José Gaos:

El Heidegger de Paz aparece no sólo como cónyuge germano del surrealismo francés, sino como el reducto de cierto humanismo existencialista que permea la vida intelectual francesa durante la posguerra. El Heidegger de Paz se acerca, de esta manera, al de Sartre... que es exclusivo de la segunda parte del El ser y el tiempo y que se limita a plantear los nexos sistemáticos con las nociones de "cura", "ser en el tiempo", y en general el "ser-ahí" de la existencia que se explica en la primera parte del mismo tratado. Esa lectura trunca es también, por cierto, la que impera entonces en el México de los años cincuenta, impulsada en parte por los cursos sobre Heidegger que años antes impartió José Gaos en la Universidad de México (sic), al igual que por su traducción e introducción a El ser y el tiempo. (Gaos había llegado a México, como exiliado de la guerra civil española, a fines de la década de los treinta) (Santí, 1997, pp. 239-240).

12 Véase la citada antología de Martínez, 1958.

13 Véase el detallado estudio de Luis Mario Schneider (1978) sobre México y el surrealismo (1925-1950), libro que no causalmente está dedicado a Luis Cardoza y Aragón. 
Según Santí: "Nunca se ha documentado, que yo sepa, esta Mexican connection (sic) de Heidegger" (Santí, 1997, p. 240). Aparte de esta polémica "lectura trunca", podría sugerirse que este Heidegger está en uso del pensamiento mexicano desde antes que Paz irrumpa en el escenario intelectual. Y un ejemplo podría ser Cardoza. Si el ordenamiento que éste da a sus artículos implica una intencionalidad identitaria, esta se deja percibir en el acento ensayístico que pone en el primero de los textos de Apolo y Coatlicue. En "Espina y Flor", en efecto, se plantea el carácter de síntesis de la obra de arte expresión de un espíritu que la engendra o produce, en este caso particular lo mexicano, forma palmaria de extrañamiento: "Nos encontramos, de pronto, en otra voz, nuestras ansias y aspiraciones; las encontramos de cuerpo entero, con rotunda presencia, como sólo las habíamos soñado" (Cardoza y Aragón, 1944, p. 11). O, dicho, si cabe, más poéticamente se percibe como intimidad "la brisa o el huracán de otro espíritu" (Cardoza y Aragón, 1944, p. 12). Cardoza deja de lado y rechaza un acercamiento científico o positivista a la obra de arte, la que resulta, así, inmanente. Es, sin embargo, una inmanencia politizada por la doctrina del mestizaje: la obra de arte es expresión ante todo de un ser americano profundo que no se separa de la religiosidad.

Aquí Cardoza incurre en los tópicos que vuelven objetos de extrañamiento a las culturas indígenas, en este caso a partir de su supuesta inmovilidad de su "manera de ser". Así el meditabundo, por antonomasia, el indígena: "Está en la tierra, inmóvil, como un árbol que piensa, caracol vegetal que se oye a sí mismo con la pureza del primer hombre que sintió la necesidad terrible de vivir no aquí, sino para la eternidad" (Cardoza y Aragón, 1944, p. 13). Cardoza concluye, así, que la cultura nacional mexicana es una "cultura de la muerte". O, con acento más evidente heideggeriano: "Todo nuestro arte es preparación para morir" (Cardoza y Aragón, 1944, p. 13). Esta argumentación quiere nutrir o pretende nutrirse de la obra de José Clemente Oroz $\mathrm{Co}^{14}$. Cardoza inventa, en otras palabras, a un Orozco que se sobrepone del pintoresquismo y revela un ser nacional interior: "Toda esa belleza de México, bárbara si queréis, Orozco nos la hace sentir" (Cardoza y Aragón, 1944, p. 18). El modelo ancestral de tal deriva identitaria es la Coatlicue como síntoma de una expresión no figurativa o, en última instancia, vanguardista. Así, en contraste con el predominio antropomórfico de la cultura grecorromana: "Lo mexicano se lleno de nubes, sueños, terror, de sombra y metafísica” (Cardoza y Aragón, 1944, p. 21).

Por supuesto, las conexiones intelectuales de estas posiciones de Cardoza son bastante amplias, y llevan a pensar, entre otras posibles fuentes y derivas, en la confrontación entre el México antiguo y la cultura clásica grecorromana

14 Hay un vínculo epistolar entre Orozco y Cardoza que parece decisivo. El muralista mexicano informa a Cardoza, por ejemplo, sobre la tradición del muralismo y del teatro popular anterior a la revolución, que Cardoza integrará polémicamente en sus libros sobre arte mexicano. Al respecto, ver Cardoza y Aragón, 1959, pp. 302-304. 
de los ateneístas encabezados por Henríquez Ureña ${ }^{15}$. Pero me quiero limitar a señalar aquí que el orden retórico de la crónica urbana no puede dar cuenta de este otro orden ensayístico y metafísico que Cardoza se (auto)impone. Se puede señalar, asimismo, una cuestión jerárquica en la estructuración retórica: el texto enseña más que enuncia. $\mathrm{O}$, en otras palabras, pospone una continuidad a lo Gómez Carrillo, cosmopolita y segregada, de la experiencia mexicana de Cardoza para favorecer, en cambio, un acercamiento identitario, quizá menos nacionalista que latinoamericano o arielista, y el cual indica sin duda un proceso de reterritorialización.

\section{Ontologías de lo popular}

En Apolo y Coatlicue, Cardoza amplifica culturalmente la perspectiva que en La nube y el reloj aparecía atada a la forma plástica y a la pintura. Este movimiento es estratégico pues permite una diversificación temática, e incluye así la pintura naíf y popular, la danza, los mercados y el surrealismo, facultando un diálogo en el campo cultural nacional y transnacional. Quisiera detenerme brevemente en su interpelación a André Bretón (“Carta a André Bretón", Apolo y Coatlicue, pp. 63-67) porque establece muy bien cierta política de apropiación y de enunciación. Lo que se apropia es, precisamente, el surrealismo, en una forma irónica y desenfadada; lo que se enuncia es una ontología de la cultura nacional-popular.

Cardoza responde aparentemente a una carta de André Bretón quien pide, dice Cardoza, "una vista panorámica del arte entre nosotros y me dice de su inminente viaje a México" (Cardoza, 1944, p. 63). (El viaje a México de Breton es de 1938 (Schneider, 1978, p. 109), la carta de Cardoza de 1936). En una estrategia que recuerda la de la enunciación de "lo real maravilloso" por Carpentier, Cardoza de-construye el surrealismo oponiéndole una realidad cultural e histórica imposible de capturar con la lógica del surrealismo. De hecho, para Cardoza, esta lógica onírica del surrealismo no es "sino pasión de exactitud, de justeza, de nitidez y de todo lo concreto" (Cardoza, 1944, p. 66). La vida cultural de México es, por el contrario, algo demasiado fluido. Su metáfora es la muerte, el arte antiguo mexicano, en efecto, "carece de otro lenguaje que no sea el de su propia muerte" (Cardoza, 1944, p. 64), analogía de la "impar muerte de México".

Sin expresarlo directamente, Cardoza propone a México como epicentro excéntrico del surrealismo. Por ejemplo, cuando propone:

Estamos en la tierra de la belleza convulsiva, en la patria de los delirios comestibles. Nuestra poesía moderna, nuestra pintura, nuestras otras artes, sólo son todavía un testimonio hermoso de la superioridad del medio (Cardoza, 1944, p. 64).

15 Para la historia ateneísta, véase García Morales, 1992. 
Parece posible pensar que esta conversión de México en especie de terreno inconsciente no es únicamente una descripción ontológica y americanista, sino también una especie de oferta cultural de circulación global (oferta que, como se sabe, va a sufrir una progresiva conversión turística a lo largo del siglo XX). La forma de la oferta es el americanismo. Sin embargo, su trasfondo enunciativo, o al menos uno de ellos, es más bien ontológico. Lo nacional mexicano implica un extrañamiento radical, su operatividad heterológica permite el diálogo y la diacronía cultural. Según Cardoza, pues, tanto la operatividad del surrealismo como la demanda ontológica aparecen amalgamadas, en el medio mexicano, con la cultura, y particularmente con la cultural popular. La cultura popular es en el México posrevolucionario una fuente primigenia; algo originario o genésico. Se trata de una lectura que estratégicamente se coloca en un momento previo al ordenamiento disciplinario de la antropología o la sociología, e incluso la historia del arte, y que sería deseable colocar como genealogía de lo que devendrá a finales del siglo en versión latinoamericana de los estudios culturales.

Un eje fundamental de esta visión ontológica sobre la cultura popular, es el gesto de abandonar lo urbano para favorecer lo profundo. Por ejemplo, en la crónica sobre los "Mercados de México" Cardoza apunta:

La ciudad es una; la nación es otra. La Capital miente siempre. A diez minutos del Zócalo nos encontramos con un aspecto nuevo de México. Sensación de potencia, de personalidad, de riqueza y una voz que se ahoga y se salva cada día. ¿No lo hemos adivinado ya en los mercados? (Cardoza y Aragón, 1944, p. 52).

El mercado es, a la vez, una reminiscencia del tiempo precortesiano y un corte sincrónico sobre lo que permanece: en ese sentido, un entrecruce fundamental entre lo urbano y lo profundo, o lo que podría llamarse un escenario de transculturación. Se sabe que los vanguardistas introducen en la retórica ensayística y cronística los hallazgos de la arqueología, la antropología y el psicoanálisis $^{16}$. Así, en Cardoza la cultura de los mercados opera como corte en que se perciben diversos estratos: "México en los mercados: un corte transversal en su médula, para el histologista" (Cardoza y Aragón, 1944, p. 51). Esto señala una arqueología humana que apunta a lo que, por otra parte, Cardoza querrá refuncionalizar en el México profundo y en el gran arte muralista. Acá la crónica deviene algo incidental, en un sentido casi musical del término: que acompaña las ideas, no necesariamente que encarna o disuelve al sujeto de la enunciación para potenciar el espacio urbano; y que, en todo caso, contribuye a diseñar el campo ideológico y ensayístico. Quisiera enfatizar, además, que no se trata de un planteamiento costumbrista o regionalista sino de uno radicalmente vanguardista que va acompañado de todo un extenso archivo de posiciones e imágenes. Solo un ejemplo, para terminar, de entre las plásticas

16 Por ejemplo, Bosshard se refiere a la "reterrirtorialización del campo estético en el campo antropopolítico" en las vanguardias americanas (Bosshard, 2013, p. 74). 
descripciones de Cardoza: "La iglesia con sus muertos bajo las piedras del atrio, recostada contra las montañas y el burrito einsteniano en la vereda encauzada entre magueyes, camino de la gran ciudad" (Cardoza y Aragón, 1944, p. 52). Ese "burrito eisteniano" cuya obvia referencia es el material del proyecto mexicano de Sergei Eisestein, de 1930, ¡Qué viva México! indica una suerte de cosmopolitismo que también opera en esa vuelta a lo profundo.

\section{Conclusiones}

En el caso de Luis Cardoza y Aragón la crónica, que acata el giro radical que ocurre del modernismo a las vanguardias, no redunda exclusivamente en la representación de un espíritu urbano, sino que intentará la representación de una profundidad identitaria y nacional. Además, esta intención proyectiva conlleva la desestabilización de fronteras genéricas por lo que la crónica aparece mixturada con el ensayo y con la crítica de arte.

Este giro no implica, por otra parte, la vuelta a un regionalismo o una inscripción conservadora. Por el contrario, la base de la intervención es el cosmopolitismo vanguardista que, de forma más radical, intenta un descentramiento de los principios transnacionales con que se incuba el cambio estético. Para lograr este cambio, Cardoza va a insertarse, aún desde su posición de extranjero o exiliado, en el debate por la identidad mexicana, en especial un discurso sobre el ser nacional que está influenciado, ente otras fuentes, por la filosofía de Heidegger.

La excentricidad en el caso de Cardoza y Aragón, implica un proceso de creación intelectual. Su estrategia vanguardista implica un doble movimiento: el de penetrar los discursos intelectuales y culturales transnacionales y el de trasladar al contexto nacional esa universalidad de los discursos. Al igual que otros grandes vanguardistas latinoamericanos y movimientos enteros dentro de las vanguardias, las posturas de Cardoza apuntan a una especie de refundación de la cultura nacional con una nueva perspectiva sobre la mundialización. Es importante, la función que adquiere en esta refundación, la cultura popular: su sistematización como fuente semiótica de identidad cuya legibilidad es, para vanguardistas como Cardoza, universal, nos da una alerta sobre la genealogía de los acercamientos culturalistas latinoamericanos.

El orden del discurso de Cardoza apunta a una mezcla retórica, que incluye elementos de la crónica y el ensayo, de la crítica de arte y la filosofía. Asimismo, su perspectiva identitaria apunta a señalar los espacios de activo mestizaje cultural, por lo que se podría considerar que se fija en escenarios de transculturación. Su perspectiva es muestra activa de la visión cultural vanguardista y sus adquisiciones diversas (surrealismo, arqueología, antropología). Queda por establecer cuánto de su acercamiento mexicano modela lo que será posteriormente su intervención en el diseño y ordenamiento de una 
cultura guatemalteca (por ejemplo, en Guatemala las líneas de su mano) que en cierto sentido es su más cara creación.

\section{Referencias}

Bosshard, Marco Thomas. (2013). La reterritorialización de lo humano: una teoría de las vanguardias americanas. Pittsburgh: IILI.

Cardoza y Aragón, Luis. (1940). La nube y el reloj. México: Ediciones de la Universidad Nacional Autónoma.

Cardoza y Aragón, Luis. (1944). Apolo y Coatlicue: ensayos mexicanos de espina y flor. México: La Serpiente Emplumada.

Cardoza y Aragón, Luis. (1953). Pintura mexicana contemporánea. México: Imprenta Universitaria.

Cardoza y Aragón, Luis. (1959). Orozco. México: Universidad Nacional Autónoma de México.

Cardoza y Aragón, Luis. (1977). Poesías completas y algunas prosas. México: Fondo de Cultura Económica.

Deleuze, Gilles \& Guattari, Félix. (2011). ¿Qué es la filosofía? Barcelona: Anagrama.

Díaz Arciniega, Víctor. (2010). Querella por la cultura "revolucionaria" (1925). México: Fondo de Cultura Económica.

García Morales, Alfonso. (1992). El Ateneo de México, 1906-1914: orígenes de la cultura mexicana contemporánea. Sevilla: Consejo Superior de Investigaciones Científicas.

González Mello, Renato. (2003). Estudio preliminar. La nube y reloj: pintura mexicana contemporánea. Luis Cardoza y Aragón. México: Universidad Nacional Autónoma de México, pp. 13-49.

Mahieux, Viviane. (2012). Urban Chroniclers in Modern Latin America: The Shared Intimacy of Everyday Life. Austin: University of Texas Press.

Martínez, José Luis. (1958). El ensayo mexicano moderno, Tomo 1. México: Fondo de Cultura Económica.

Montaldo, Graciela. (2013). “Guía Rubén Darío”. En Graciela Montaldo (ed.), Rubén Darío. Viajes de un cosmopolita extremo. Buenos Aires: Fondo de Cultura Económica.

Pacheco, José Emilio. (1977). "Prólogo”. Cardoza y Aragón. Poesías completas. México: Fondo de Cultura Económica, pp. 7-26. 
Rodríguez Cascante, Francisco. (2012). "De Fez a Tánger: imágenes de identidad en la literatura guatemalteca del siglo XX”. Candil, (12), 89-100.

Roque-Baldovinos, Ricardo. (2009). "Exotismo y autoridad cultural modernista: dos viajeros centroamericanos por el Extremo Oriente". En Valeria Gringber Pla y Ricardo Roque-Baldovinos (eds.), Tensiones de la modernidad: del modernismo al realismo. Guatemala: F\&G, pp. 167-188.

Santí, Enrico Mario. (1997). El acto de las palabras: estudios y diálogos con Octavio Paz. México: Fondo de Cultura Económica.

Schneider, Luis Mario. (1978). México y el surrealismo (1925-1950). México: Arte y Libros.

Sznajder, Mario con Luis Roniger. (2013). La política del destierro y el exilio en América Latina. México: Fondo de Cultura Económica. 